\author{
RESEARCH ARTICLE \\ 10.1029/2020JC016365 \\ Key Points: \\ - An eddying global simulation \\ represents well the observed vertical \\ structure of the ACC transport \\ through Drake Passage \\ - The time-mean total ACC transport \\ likely falls in between the DRAKE \\ and cDrake estimates, that is, 141 \\ and $173 \mathrm{~Sv}$ \\ - Both baroclinic and barotropic \\ components are important for the \\ temporal variability of the ACC \\ transport
}

Correspondence to:

$\mathrm{X} . \mathrm{Xu}$,

xxu3@fsu.edu

Citation:

Xu, X., Chassignet, E. P., Firing, Y. L., \& Donohue, K. (2020). Antarctic

Circumpolar Current transport through Drake Passage: What can we learn from comparing high-resolution model results to observations? Journal of Geophysical Research: Oceans, 125 e2020JC016365. https://doi.org/ 10.1029/2020JC016365

Received 1 MAY 2020 Accepted 12 JUN 2020 Accepted article online 17 JUN 2020

(c)2020. American Geophysical Union. All Rights Reserved.

\section{Antarctic Circumpolar Current Transport Through Drake Passage: What Can We Learn From Comparing High-Resolution Model Results to Observations?}

\author{
Xiaobiao Xu $^{1}$ DD, Eric P. Chassignet ${ }^{1}$ D, Yvonne L. Firing ${ }^{2}$ iD, and Kathleen Donohue ${ }^{3}$ iD \\ ${ }^{1}$ Center for Ocean-Atmospheric Prediction Studies, Florida State University, Tallahassee, FL, USA, ${ }^{2}$ National \\ Oceanography Centre, Southampton, UK, ${ }^{3}$ Graduate School of Oceanography, University of Rhode Island, Narragansett, \\ RI, USA
}

\begin{abstract}
Uncertainty exists in the time-mean total transport of the Antarctic Circumpolar Current (ACC), the world's strongest ocean current. The two most recent observational programs in Drake Passage, DRAKE and cDrake, yielded transports of 141 and $173.3 \mathrm{~Sv}$, respectively. In this paper, we use a realistic $1 / 12^{\circ}$ global ocean simulation to interpret these observational estimates and reconcile their differences. We first show that the modeled ACC transport in the upper 1,000 $\mathrm{m}$ is in excellent agreement with repeat shipboard acoustic Doppler current profiler (SADCP) transects and that the exponentially decaying transport profile in the model is consistent with the profile derived from repeat hydrographic data. By further comparing the model results to the cDrake and DRAKE observations, we argue that the modeled 157.3 Sv transport, that is, approximately the average of the cDrake and DRAKE estimates, is actually representative of the time-mean ACC transport through the Drake Passage. The cDrake experiment overestimated the barotropic contribution in part because the array undersampled the deep recirculation southwest of the Shackleton Fracture Zone, whereas the surface geostrophic currents used in the DRAKE estimate yielded a weaker near-surface transport than implied by the SADCP data. We also find that the modeled baroclinic and barotropic transports are not correlated; thus, monitoring either baroclinic or barotropic transport alone may be insufficient to assess the temporal variability of the total ACC transport.
\end{abstract}

Plain Language Summary The Antarctic Circumpolar Current (ACC) flows eastward around the globe in the Southern Ocean and is the world's strongest ocean current. Yet, we still do not know accurately the magnitude of its volume transport: The two most recent observational programs in Drake Passage, DRAKE and cDrake, yielded transport values of 141 and $173.3 \mathrm{~Sv}\left(1 \mathrm{~Sv}=10^{6} \mathrm{~m}^{3} / \mathrm{s}\right)$, respectively. This study uses a high-resolution global ocean model to better understand these observational estimates. The modeled transport is shown to be in excellent agreement with direct measurements of velocity, which can be made in the top 1,000 $\mathrm{m}$ of the water column, and with the transport derived from temperature-salinity measurements for the full water column. Based on more detailed comparisons with the model, we argue that the cDrake experiment overestimated the transport partially because the array undersampled the near bottom flow, whereas the surface velocity used in the DRAKE estimate underestimated the near-surface transport, and thus, the time-mean ACC transport likely falls between these two observational estimates.

\section{Introduction}

The Antarctic Circumpolar Current (ACC) is a strong oceanic current that flows eastward around Antarctica. It connects the Pacific, Atlantic, and Indian Oceans to its north and is the primary means of interbasin exchange, enabling a truly global overturning circulation (e.g., Gordon, 1986; Schmitz, 1996; Talley, 2013). Across the ACC, the constant-density surfaces or isopycnals exhibit a strong north-to-south tilt, allowing water masses to undergo large vertical excursions without crossing isopycnals (e.g., Marshall \& Speer, 2012; Sverdrup, 1933). An accurate knowledge of the ACC transport and its horizontal and vertical structure is fundamental to understand the current's influence on the global circulation and ocean transports of heat, fresh water, and carbon. 


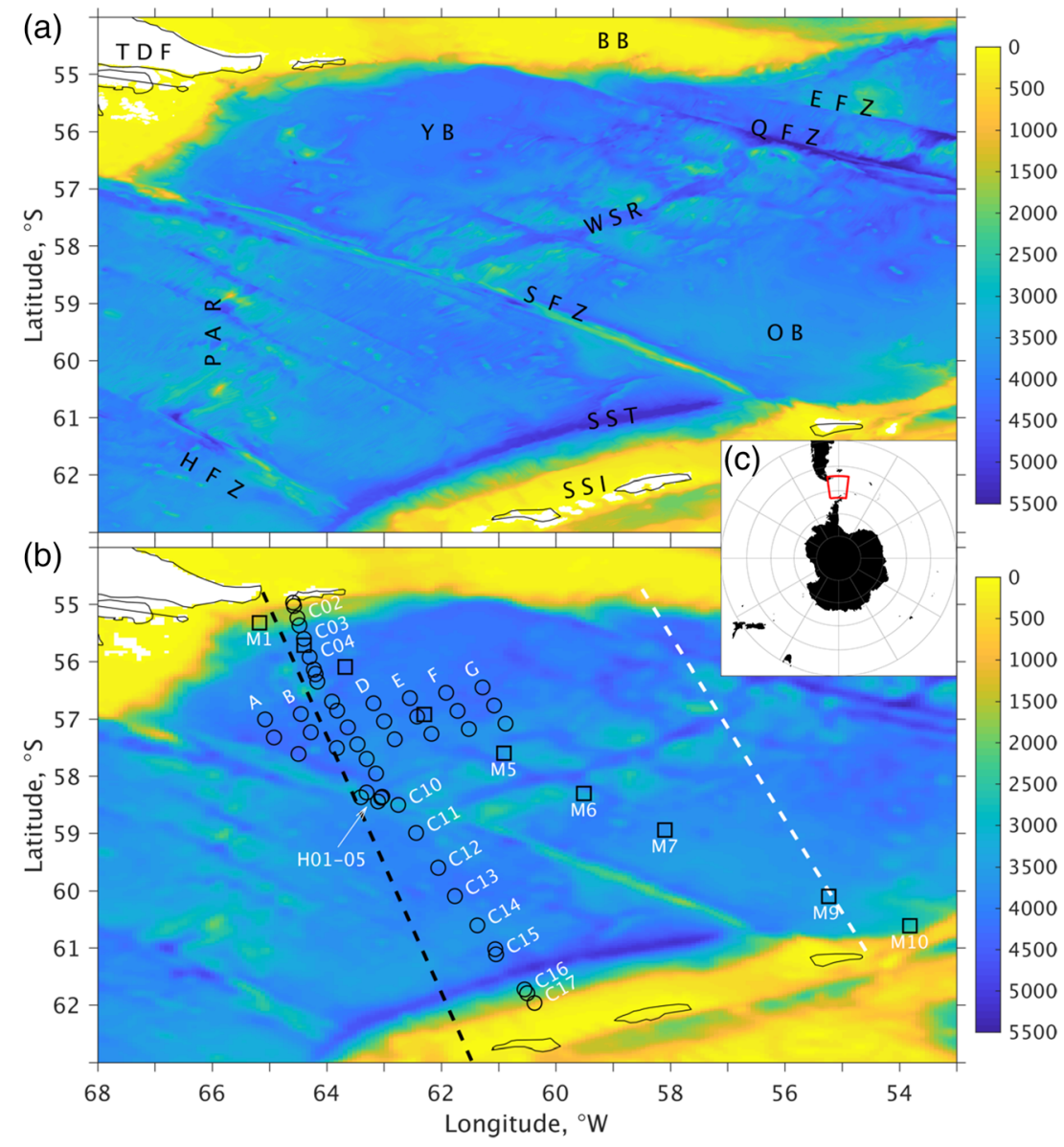

Figure 1. (a) Bathymetry of Drake Passage with $1 \mathrm{~km}$ resolution, after a 5-point average applied to the original $200 \mathrm{~m}$ resolution map of multibeam data provided by Bohoyo et al. (2019), and for comparison, (b) model bathymetry with $1 / 12^{\circ}$ (around $5 \mathrm{~km}$ in this area) resolution; (c) the location of the Drake Passage (red box) with respect to Antarctia and South America. In panel (a) the marked topographic features are Tierra Del Fuego (TDF), Hero Fracture Zone (HFZ), Shackleton Fracture Zone (SFZ), Quest Fracture Zone (QFZ), Endurance Fracture zone (EFZ), Phoenix Antarctic Ridge (PAR), West Scotia Ridge (WSR), Yaghan Basin (YB), Ona Basin (OB), Burdwood Bank (BB), South Shetland Trench (SST), and South Shetland island (SSI). In panel (b), the dashed black and white lines indicate locations of the shipboard ADCP section (Firing et al., 2011) and the WOCE repeat hydrographic section SR1b (Cunningham et al., 2003), respectively; the black circles indicate current meter/CPIES mooring locations in the cDrake program (Chidichimo et al., 2014; Donohue et al., 2016), and the black squares indicate current meter mooring locations in the DRAKE program (Koenig et al., 2014).

Drake Passage, located between Antarctica's South Shetland Islands and the southernmost tip of South America (Figure 1), is an ACC chokepoint and the location of many long-term sustained monitoring programs (e.g., Meredith et al., 2011). Based on moored current meter and ship-based hydrographic data obtained during the International Southern Ocean Studies (ISOS) program in the late 1970s and early 1980s, Whitworth (1983) and Whitworth and Peterson (1985) derived the canonical full-depth ACC transport of $134 \pm 15 \mathrm{~Sv}\left(1 \mathrm{~Sv}=10^{6} \mathrm{~m}^{3} / \mathrm{s}\right)$. Cunningham et al. (2003) reanalyzed the ISOS data and increased the uncertainty to $27 \mathrm{~Sv}$. Since the ISOS program, there have been four major observational programs aimed at quantifying the time mean ACC transport in Drake Passage:

1. The SR1b repeat hydrographic section: Cunningham et al. (2003) estimated an average baroclinic transport of $136.7 \pm 7.8 \mathrm{~Sv}$ (standard deviation) relative to the bottom from six repeat hydrographic sections in 1993-2000 along the World Ocean Circulation Experiment (WOCE) SR1b line. Averaging over 16 sections (1993-2009) as in Meredith et al. (2011) or all 25 sections (1993-2020) as in this study does not much change their estimate $(136.7 \pm 6.9$ or $135.3 \pm 10.2 \mathrm{~Sv}$, respectively). We hereafter refer to these observations as SR1b. 
2. Repeat shipboard acoustic Doppler current profiler (SADCP) transects: Firing et al. (2011) estimated a total transport of $95 \pm 2 \mathrm{~Sv}$ (standard error of the mean) in the top 1,000 $\mathrm{m}$ of the water column, based on 53 transects, over 4.5 years, of high-resolution SADCP velocity measurements. We hereafter refer to this data set as SADCP.

3. The DRAKE mooring array: Koenig et al. (2014) estimated a full-depth transport of $141 \pm 2.7 \mathrm{~Sv}$ (standard error of the mean) of which $136 \mathrm{~Sv}$ were baroclinic and $5 \mathrm{~Sv}$ barotropic, based on a combination of moored current meter data from the DRAKE program (2006-2009) and satellite altimetry data (1993-2012). We hereafter refer to these estimates as DRAKE.

4. The cDrake mooring array: Chidichimo et al. (2014) and Donohue et al. (2016) estimated a full-depth transport of $173.3 \pm 10.7 \mathrm{~Sv}$, consisting of 127.7 Sv baroclinic transport and 45.6 Sv barotropic, based on the high-resolution moored bottom current and pressure measurements of the cDrake program (2007-2011). We hereafter refer to these estimates as cDrake.

The baroclinic transport as defined here refers to the geostrophic flow referenced to zero at bottom, which can be inferred directly from hydrographic observations alone since it is in balance with the horizontal density gradients. The corresponding barotropic transport refers to the flow at the bottom multiplied by the water depth (e.g., Peña-Molino et al., 2014). This separation between barotropic and baroclinic flows differs from what is commonly used in theoretical and modeling studies, that is, barotropic as the depth-averaged flow and baroclinic as the departure from the vertical average. The baroclinic component (by the definition used here) constitutes the majority of the total ACC transport and is relatively well-established at Drake Passage. The barotropic component, on the other hand, is not negligible and in practice is far more difficult to measure accurately as it relies on knowing velocities over the range of bottom depths with high horizontal resolution. It is fundamental to obtain an accurate knowledge of both components because each plays a different role in the dynamical balances of the ACC (Olbers et al., 2004).

The observational studies listed above show that there remains a large uncertainty in the estimate of the time-mean ACC transport through Drake Passage, especially in the barotropic component. Even less is certain about variability on interannual and longer time scales. In situ bottom pressure measurements have been used to study transport variability and to reveal how it relates to sea level around Antarctica (e.g., Hughes et al., 1999), with connections to Southern Hemisphere westerly winds summarized by correlations with the Southern Annular Mode (SAM) index (e.g., Meredith et al., 2004), which numerical model results predict will persist over a range of time scales (Hughes et al., 2014). Atmospheric measurements indicate that the westerly winds in the Southern Ocean have intensified since the 1970s in conjunction with a higher SAM index (Thompson \& Solomon, 2002); yet, none of the long ACC transport time series (Koenig et al., 2014; Meredith et al., 2011) show a clear long-term trend. This has been explained by the eddy saturation hypothesis (Hallberg \& Gnanadesikan, 2001) supported by numerical model results (e.g., Hallberg \& Gnanadesikan, 2006; Munday et al., 2013) and consistent with some surface observations (Hogg et al., 2015) but has not yet been verified by direct observations of transport. The challenge for an observational program is in monitoring the ACC transport with fine enough spatial and temporal sampling to resolve the highly variable current across the $800 \mathrm{~km}$ wide, $4,000 \mathrm{~m}$ deep passage. The need for relatively high-frequency temporal sampling to prevent aliasing has been described by Meredith and Hughes (2005), while the problem of resolving a vertical structure which varies spatially and over time has been raised by Hughes et al. (2014). High-resolution numerical models are not limited in either regard and, by filling in the gaps, can provide additional insights into the ACC structure and variability, once good agreement between model and observations is established.

In this paper, we compare high-resolution global model outputs to the cDrake, DRAKE, SADCP, and SR1b data and argue that our model's $157.3 \mathrm{~Sv}$ mean transport, that is, approximately the average of the cDrake and DRAKE estimates, is actually representative of the time-mean ACC transport through the Drake Passage. We surmise that the cDrake transport overestimates the barotropic contribution in part because the array undersamples the tight recirculation southwest of the Shackleton Fracture Zone, whereas the surface geostrophic currents used in the DRAKE estimate yield a weaker near-surface transport than the SADCP data. We also find that the modeled baroclinic and barotropic transports are not correlated, implying that monitoring either component alone may be insufficient to assess the temporal variability of the total ACC transport. 
Table 1

Viscosity and Diffusion Coefficients Used in the $1 / 12^{\circ}$ Global Ocean Simulation

\begin{tabular}{ll}
\hline Parameters & \multicolumn{1}{c}{ Values } \\
\hline Laplacian coefficient for momentum & $20 \mathrm{~m}^{2} \mathrm{~s}^{-1}$ \\
Biharmonic diffusive velocity for momentum & $1 \mathrm{~cm} \mathrm{~s}^{-1}$ \\
Biharmonic diffusive velocity for layer thickness & $1.5 \mathrm{~cm} \mathrm{~s}^{-1}$ \\
Laplacian diffusive velocity for tracers & $0.5 \mathrm{~cm} \mathrm{~s}^{-1}$ \\
\hline
\end{tabular}

The paper is structured as follows: In section 2, we summarize the configuration of the numerical simulation and the locations of the observations with respect to key bathymetric features of Drake Passage. In section 3, the modeled ACC is compared in detail with (a) the results based on the repeat SADCP and the SR1b hydrographic observations and (b) the results of the cDrake and DRAKE observations. The findings are summarized and discussed in section 3.3.

\section{Numerical Simulation and Drake Passage Observations}

\subsection{Numerical Simulation}

The numerical results used in this study are from a multi-decadal global ocean and sea-ice simulation based on the HYbrid Coordinate Ocean Model (HYCOM, Bleck, 2002, Chassignet et al., 2003) and the Community Ice Code (CICE4, Hunke \& Lipscomb, 2008). The simulation is described in detail in Chassignet et al. (2020) as part of a coarse- versus high-resolution global ocean model comparison effort. The model domain covers the global ocean from $80^{\circ} \mathrm{S}$ to $90^{\circ} \mathrm{N}$ with a nominal horizontal resolution of $1 / 12^{\circ}$ and vertical resolution of 36 layers. The horizontal grid uses a Mercator projection south of $47^{\circ} \mathrm{N}$ and a curvilinear bipolar grid north of this latitude to avoid singularity at the North Pole. The simulation is initialized with zero velocity and temperature and salinity from an ocean climatology of the Generalized Digital Environmental Model (GDEM4, Carnes, 2009). The atmospheric forcing uses the latest JRA55-do (Tsujino et al., 2018), which covers a 61-year period from 1958 to 2018. The diffusivity parameters used in the simulation are listed in Table 1. These parameter values are the minimum required for numerical stability.

\subsection{Drake Passage Observations}

In order to set the stage for the model-data comparisons in the next section, here we provide some detail on key bathymetry features of the Drake Passage and the four major observational programs, that is, the repeat hydrographic surveys along the SR1b line, the repeat SADCP transects, the moored current meter array of the DRAKE program, and the moored bottom current and pressure measurements of the cDrake program.

Running across Drake Passage (Figure 1a) is the Shackleton Fracture Zone, a northwest-to-southeast ridge which rises several hundreds to thousands of meters above the surrounding seafloor from Cape Horn of South America to Elephant Island of the South Shetland Islands. To the west of the Shackleton Fracture Zone, the Phoenix Antarctic Ridge and Hero Fracture Zone extend southward near $66^{\circ} \mathrm{W}$. To the east, the West Scotia Ridge separates Drake Passage into Yaghan Basin to the north and Ona Basin to the south. The bathymetry in the model (Figure $1 \mathrm{~b})$, with $1 / 12^{\circ}$ resolution ( $\sim \mathrm{km}$ in Drake Passage) represents the large-scale features well.

The repeat SADCP surveys, which directly measure the velocity in the top 1,000 $\mathrm{m}$ of the water column, run between southward and southeastward from the Le Maire Strait (located at the eastern extremity of the Argentine portion of Tierra Del Fuego) to a range of points along the South Shetland Islands. The most representative SADCP section runs at a $23.7^{\circ}$ angle (measured counterclockwise from north; dashed black line in Figure 1b) and was defined as the most "common" section by Firing et al. (2011). Data from this line were used by Firing et al. (2011) to determine the locations of the ACC fronts and to calculate volume transport for the top 1,000 m. Slightly to the east, the cDrake observations (Chidichimo et al., 2014; Donohue et al., 2016) include a high-resolution trans-passage mooring line that is used to estimate the ACC transports as well as a local dynamic array of three sections to map the mean and eddying circulation in the Yaghan Basin (black circles labeled A-G in Figure 1b). The DRAKE observations (Koenig et al., 2014) consist of a moored section that runs southeastward $\left(\sim 45^{\circ}\right)$ to the east of the Shackleton Fracture Zone (black squares in Figure 1b). Farther east, the WOCE hydrographic section SR1b runs south-southeastward across the passage ending at Elephant Island (white line in Figure 1b). SR1b temperature and salinity profiles have been used to derive the baroclinic transport of the ACC (e.g., Cunningham et al., 2003; Meredith et al., 2011).

\section{Model-Data Comparison}

In this section, we first examine the variability of the modeled total ACC transports in 1979-2018 (section 3.1), then compare the spatial structure and temporal variability of the modeled ACC to 


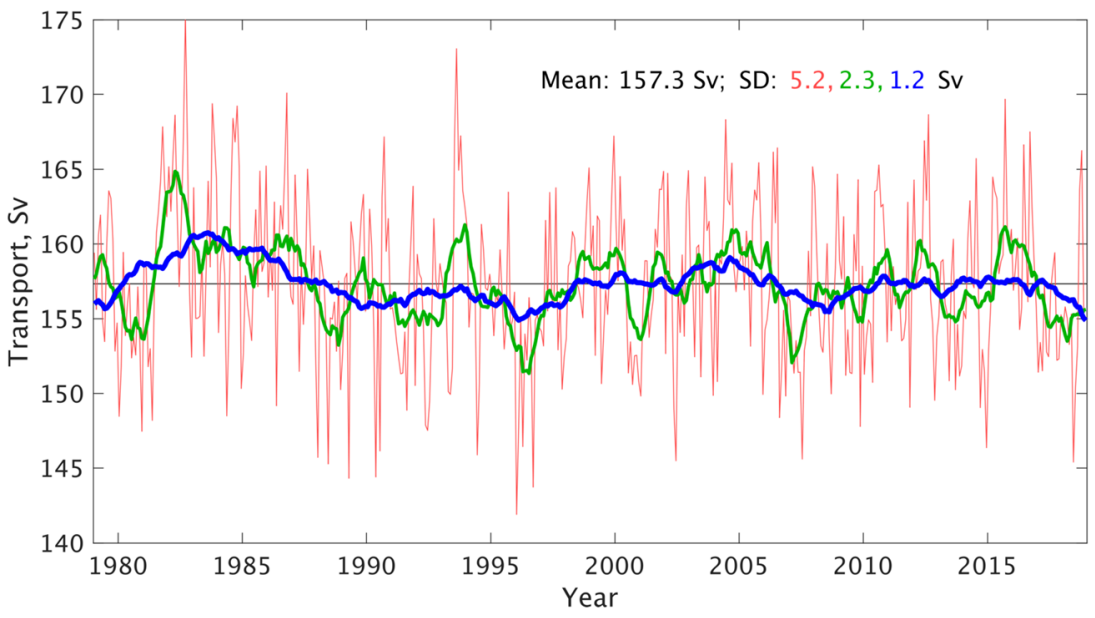

Figure 2. Time series of the modeled total transport of the ACC through Drake Passage from 1979 to 2018 based on a $1 / 12^{\circ}$ global simulation. The red, green, and blue lines are 1-month, 1-year, and 4-year moving averages respectively. The 40-year mean transport is $157.3 \mathrm{~Sv}$, with a standard deviations of 5.2, 2.3, and 1.2 Sv for monthly, annual, and 4-year means. The modeled ACC transport exhibits no sign of a long-term trend.

observations at the repeat SADCP and hydrographic sections to establish the realism of the model transport structure (section 3.2). Finally, we compare the model results with the cDrake and DRAKE observations to interpret the difference in their transport estimates (section 3.3).

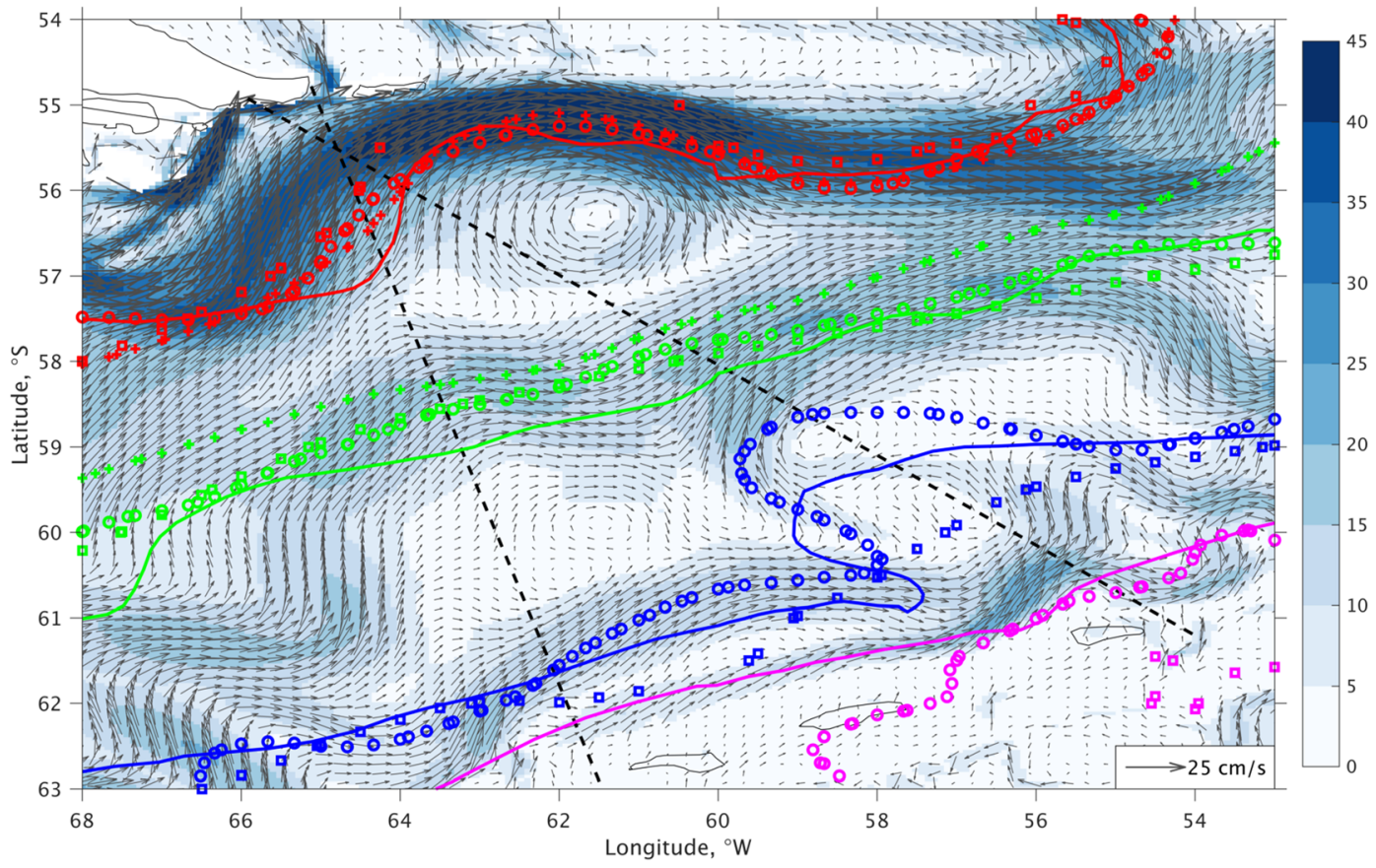

Figure 3. Modeled 40-year (1979-2018) mean flow speed (color shading, cm/s) and direction (vectors) for the upper $1,000 \mathrm{~m}$ based on a $1 / 12^{\circ}$ global simulation, along with the observed ACC frontal locations: the Subantarctic Front (SAF) in red, Polar Front (PF) in green, South ACC front (SACCF) in blue, and southern boundary front (SBdy) in magenta. The thicker vectors with a constant length scale of $25 \mathrm{~cm} / \mathrm{s}$ indicate strong currents $(25 \mathrm{~cm} / \mathrm{s}$ or higher). The solid lines are derived by Orsi et al. (1995) based on hydrographic data; the circles, squares, and cross symbols are derived by Kim and Orsi (2014), Sokolov and Rintoul (2009), and Sallée et al. (2008), respectively, based on the sea surface height data. The dashed black line indicates the location of the most common section of the shipboard ADCP surveys (Firing et al., 2011) and the DRAKE section (Koenig et al., 2014). 


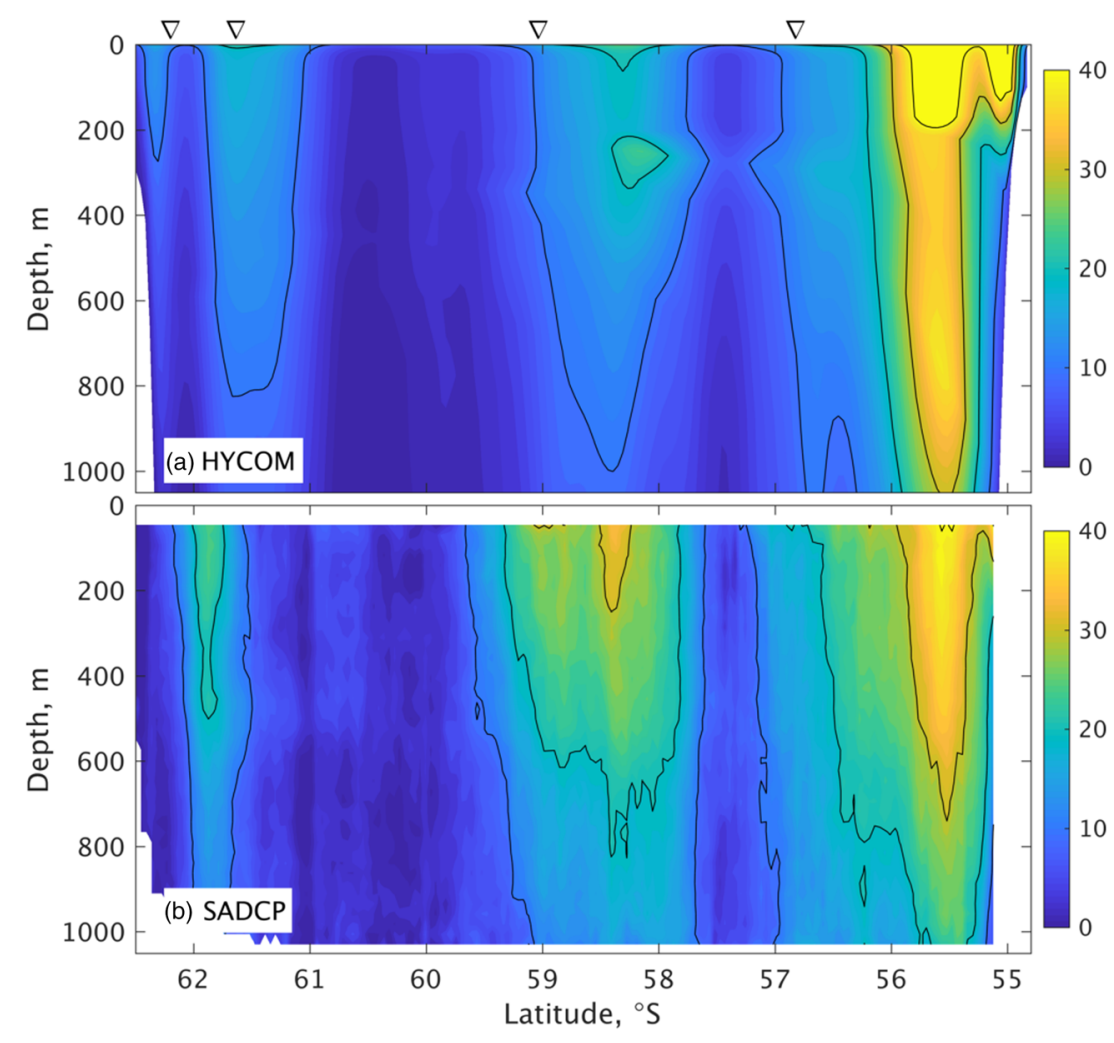

Figure 4. A comparison of the modeled (a) and observed (b) velocity $(\mathrm{cm} / \mathrm{s})$ normal to the most common SADCP section (black dashed line in Figure 3) over the top 1,000 m. The four triangles in panel (a) from north to south denote the locations of SAF, PF, SACCF, and SBby from Orsi et al. (1995) based on hydrographic data (colored lines in Figure 3).

\subsection{Model Total Transport Through Drake Passage}

Figure 2 displays the modeled monthly mean ACC transports through the Drake Passage from 1979 to 2018, integrated from land to land and surface to bottom along $65^{\circ} \mathrm{W}$. The 40 -year mean transport is $157.3 \mathrm{~Sv}$, and the transport variability decreases substantially as averaging timescales increase: The standard deviations of daily, monthly, annual, and 4-year mean transports are 7.3, 5.7, 2.3, and $1.2 \mathrm{~Sv}$, respectively. This result suggests that 4-year-long observations (such as cDrake and DRAKE) should provide a good representation of the long-term average.

As stated in the introduction, atmospheric measurements indicate that the westerly winds in the Southern Ocean have intensified since the 1970s in conjunction with a higher SAM index. The increase in westerly winds is also present in the JRA55-do forcing (not shown); yet, the modeled ACC transports exhibit no sign of a long-term trend (Figure 2). This lack of response of the wind-driven ACC to long-term changes in the zonal wind is in agreement with previous results from high-resolution models, where the strengthening of winds generates more ACC eddy activity rather than stronger total transport (e.g., Hallberg \& Gnanadesikan, 2006; Morrison \& Hogg, 2013; Munday et al., 2013).

\subsection{SADCP and SR1b Sections}

Figure 3 displays the 40-year average model velocity in the top 1,000 $\mathrm{m}$ of the water column (full water column where shallower than 1,000 m) through Drake Passage, superimposed by the climatological location of the ACC fronts summarized in Kim and Orsi (2014, their Figure 6). From north to south, the red, green, blue, and magenta lines are the Subantarctic Front (SAF), Polar Front (PF), South ACC front (SACCF), and southern boundary front (SBdy), respectively, derived by Orsi et al. (1995) from hydrographic data. The colored circles, squares, and cross symbols are the locations of fronts derived from SSH data by Kim and Orsi (2014), Sokolov and Rintoul (2009), and Sallée et al. (2008), respectively. There is a broad agreement in these observed frontal locations, especially for the SAF and PF, as well as between the modeled and 


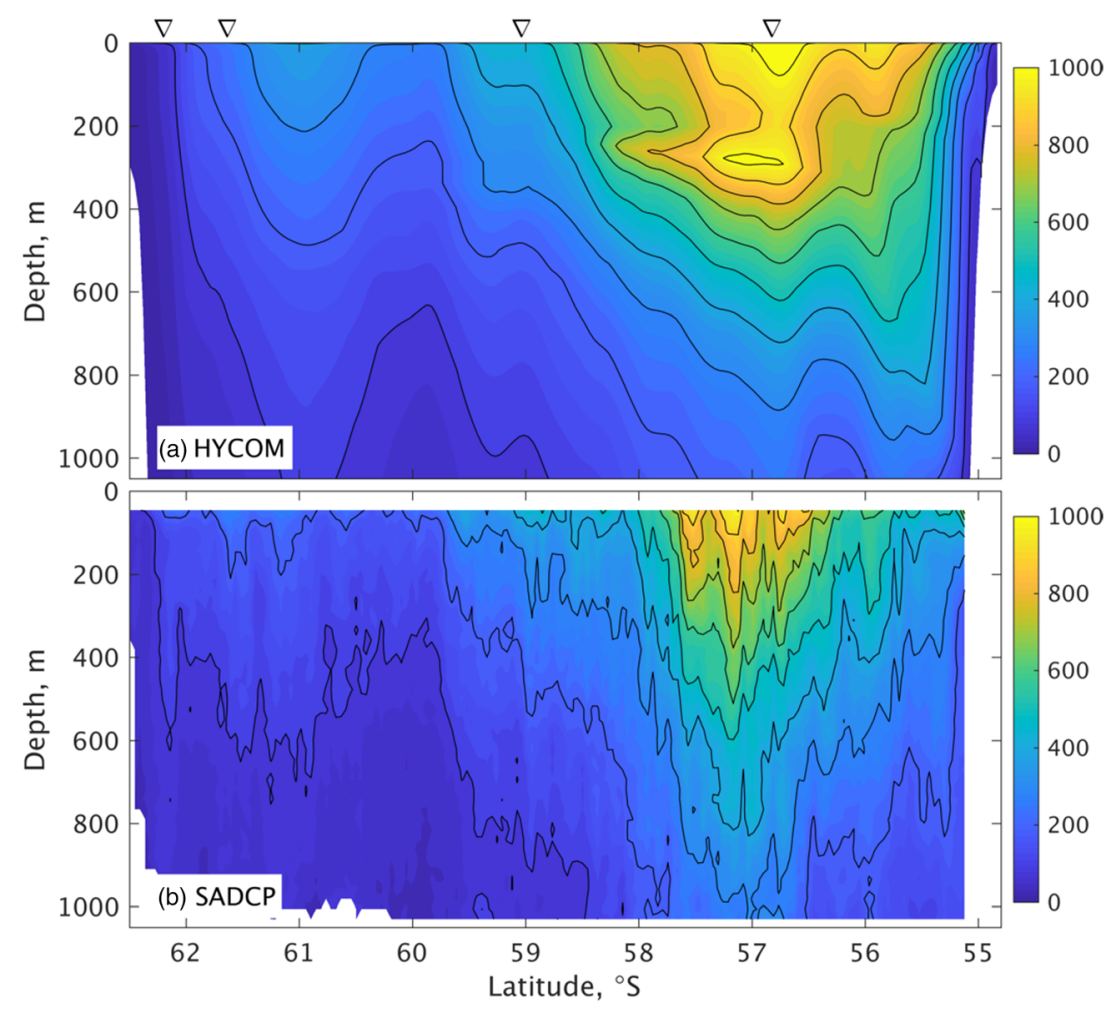

Figure 5. A comparison of the modeled (a) and observed (b) Eddy Kinetic Energy (EKE, $\mathrm{cm}^{2} / \mathrm{s}^{2}$ ) within the top 1,000 $\mathrm{m}$ over the most common SADCP section (black dashed line in Figure 3). The four triangles in panel (a) from north to south denote the locations of SAF, PF, SACCF, and SBby from Orsi et al. (1995) based on hydrographic data (colored lines in Figure 3).

observed frontal locations. There are also some discrepancies, for instance, in the exact location of SACCF near $58^{\circ} \mathrm{W}$ among different observations and in the exact location where the SAF starts to steer northward west of $64^{\circ} \mathrm{W}$ between model and observations. In particular, the SBdy front as derived from altimetry SSH data is often found further to the south than that derived from hydrographic measurements (Orsi et al., 1995), and the differences can be quite large. This may imply a weak SSH signature for the SBdy front.

For a more detailed comparison of the front locations and magnitudes, we focus on the modeled and observed mean velocity normal to the "common" SADCP section introduced in the previous section (dashed black line in Figure 3). The model results (Figure 4a) show four high-velocity cores (fronts): SAF at $55-56^{\circ} \mathrm{S}$, $\mathrm{PF}$ at $58-59^{\circ} \mathrm{S}, \mathrm{SACCF}$ at $61-62^{\circ} \mathrm{S}$, and a weak SBdy close to the Antarctic slope. The last is not well-resolved in the SADCP data (Figure 4b), but the location of the three main ACC fronts (SAF, PF, and SACCF) in the model is consistent with the observations. Although front locations are consistent, the modeled SAF is stronger, and the PF is notably weaker than in observations (Figure 4). The ACC fronts are not always separated from each other flowing eastward but rather split and merge from time to time alongstream (e.g., Figure 3). Before reaching the SADCP section, some modeled flow splits from the SAF and merges into the PF near $66^{\circ} \mathrm{W}$. Such steering and splitting/merging lead to high eddy kinetic energy (EKE) between the SAF and $\mathrm{PF}$ and a secondary high EKE north of the SACCF, evident (Figure 5) in both observations and model results, with the model exhibiting somewhat higher values. The EKE is defined as the average energy of the time-varying flow:

$$
\mathrm{EKE}=\overline{\frac{\mathbf{1}}{\mathbf{2}}\left((\boldsymbol{u}-\overline{\boldsymbol{u}})^{2}+(\boldsymbol{v}-\overline{\boldsymbol{v}})^{2}\right)}
$$

in which $\boldsymbol{u}$ and $\boldsymbol{v}$ represent the zonal and meridional components of the velocity and the bar denotes a long time average (1979-2018 for the model). The steering, splitting, and merging of the ACC fronts are 


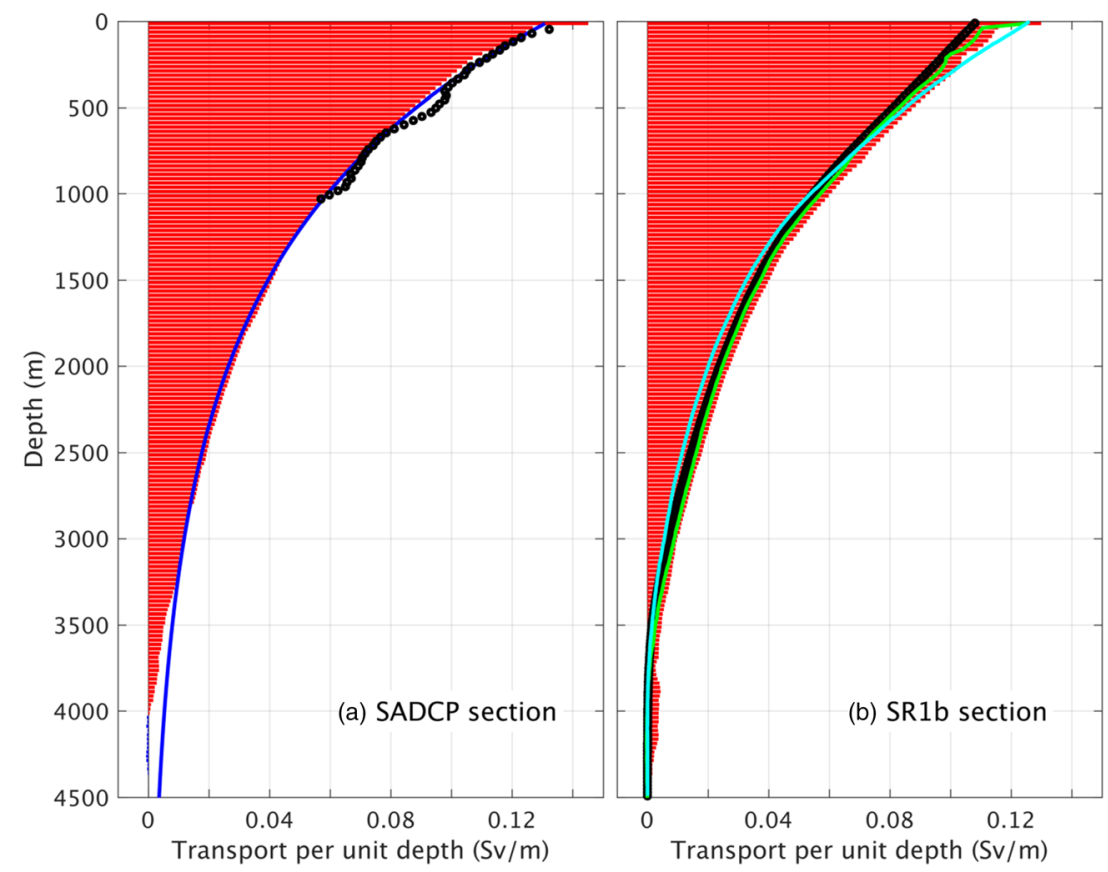

Figure 6. Vertical profile of transport per unit depth as a function of depth at (a) SADCP section and (b) repeat WOCE hydrographic section SR1b. The red horizontal bars are the modeled total transport. In panel (a), the blue line is a fitted exponential function $\boldsymbol{U}=\boldsymbol{U}_{\mathbf{0}} \boldsymbol{e}^{-\boldsymbol{z} / \boldsymbol{z}_{0}}$ (with $\boldsymbol{U}_{\mathbf{0}}$ of $0.132 \mathrm{~m} \mathrm{~s}^{-1}$ and $z_{0}$ of $1,240 \mathrm{~m}$ ); the black circles are SADCP observations from Firing et al. (2011) — Note that there is no SADCP measurements in the top $25 \mathrm{~m}$ and that the model shows higher transport because of the ageostrophic Ekman contribution; in panel (b), the black circles are baroclinic transport based on the 25 hydrographic surveys (1993-2020); the cyan and green lines are the modeled baroclinic transport calculated from modeled time mean density profiles and by subtracting the barotropic component from the total transport, respectively.

modulated by the bottom bathymetry (LaCasce \& Isachsen, 2010), and an accurate modeling of the SAF versus PF partitioning of the total ACC transport may require an accurate presentation of the fine-scale bathymetry details, especially the Phenix Antarctic Ridge (PAR) that sits directly to the upstream of the SADCP section (Figure 1).

The vertical profile of the modeled transport per unit depth through Drake Passage (Figure 6a) agrees well with the SADCP results for 0-1,000 m: The transport rate is about $0.13 \mathrm{~Sv}$ per meter near the surface and decreases to half $(0.06 \mathrm{~Sv}$ per meter) at $1,000 \mathrm{~m}$. The total model transport is $92.7 \mathrm{~Sv}$ within the first $1,000 \mathrm{~m}$, close to the $95 \mathrm{~Sv}$ of Firing et al. (2011). Firing et al. (2011) further estimated a total ACC transport of $154 \mathrm{~Sv}$ by extending the SADCP transport profile to the bottom assuming an exponential decay. The model transport does exhibit an exponential decay with depth, and a simple fit to $\boldsymbol{U}(\boldsymbol{z})=\boldsymbol{U}_{\mathbf{0}} \boldsymbol{e}^{-\boldsymbol{z} / \boldsymbol{z}_{0}}$ gives $\boldsymbol{U}_{\mathbf{0}}$ of $0.132 \mathrm{~Sv}$ per meter and a vertical scale $\boldsymbol{z}_{\mathbf{0}}$ of $1,240 \mathrm{~m}$ (blue line in Figure $6 \mathrm{a}$ ). This $\boldsymbol{z}_{\mathbf{0}}$ value is comparable to the average length scale for velocity profiles in the Southern Ocean State Estimate (SOSE) presented by Firing et al. (2011). The modeled transport in Figure 6a noticeably differs from the exponential fit mostly in top $25 \mathrm{~m}$ (due to Ekman contribution) and below 3,500 $\mathrm{m}$ (bottom friction). An exponential decay of velocity has been noted in earlier coarse-resolution simulations (e.g., Killworth, 1992), and this was the motivation behind the development of equivalent barotropic ACC models (see review by LaCasce \& Isachsen, 2010). However, a vertical profile of modeled transport has never been documented.

The modeled transport profile in Figure 6a leads to a total transport of $157.3 \mathrm{~Sv}$. The question then arises: Do observations support an exponentially decaying ACC transport as a function of depth? After all, the SADCP surveys only sample the top 1,000 m, and Firing et al. (2011) found that a linear function fits the observations over that range as well as the exponential function. The observed vertical profile of the mean baroclinic transport derived from the 25 repeat surveys along SR1b (1993-2020, Figure 6b, dotted black line) has a similar exponential decay to that of the model baroclinic transport at SR1b, computed by either (a) using the 

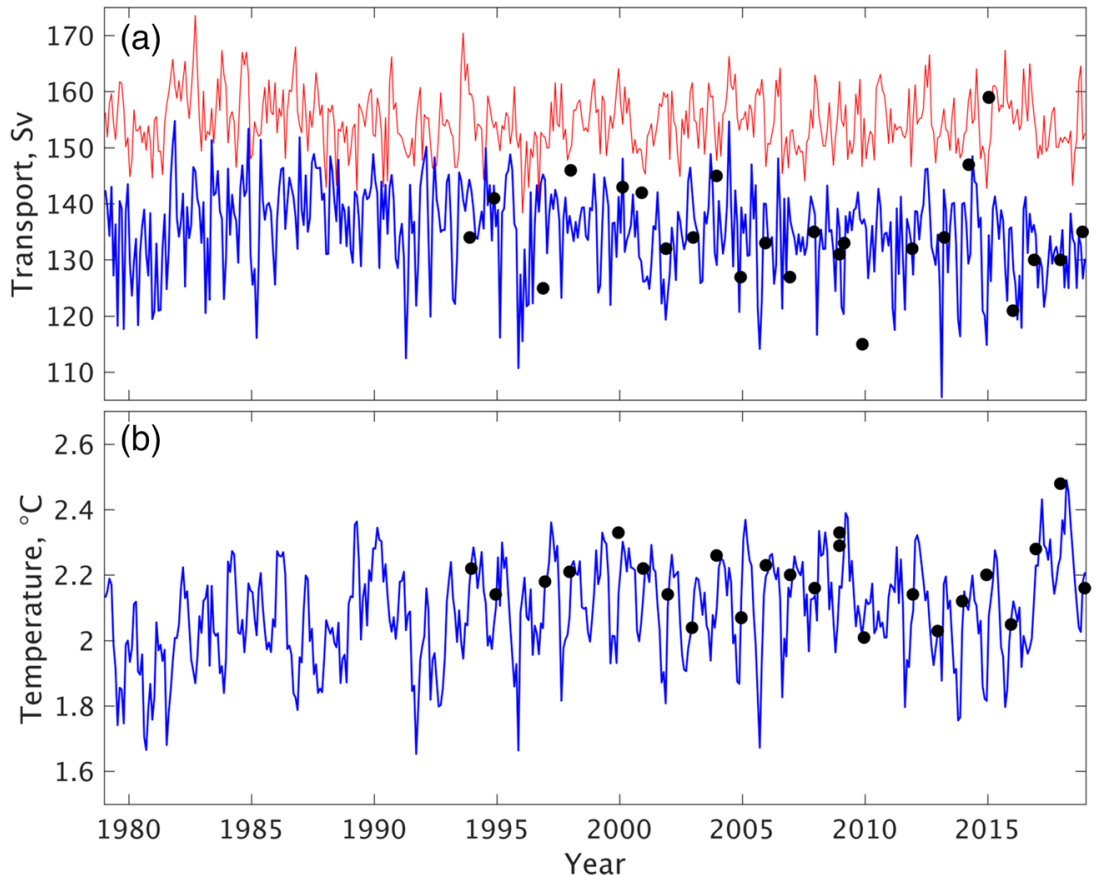

Figure 7. Monthly mean (a) volume transports and (b) temperature across the hydrographic section SR1b. The red and blue lines in (a) are modeled total and baroclinic transports, respectively; the blue line in (b) is the modeled baroclinic transport-weighted mean potential temperature. The transport-weighted potential temperature is computed by dividing the integral of potential temperature times baroclinic transport per unit width and depth by the baroclinic transport. The black dots are observed values based on 24 hydrographic surveys in 1993-2018 (note that a seasonal adjustment was applied for the temperature in the observations to remove the seasonal cycle-December values shown in panel (b).

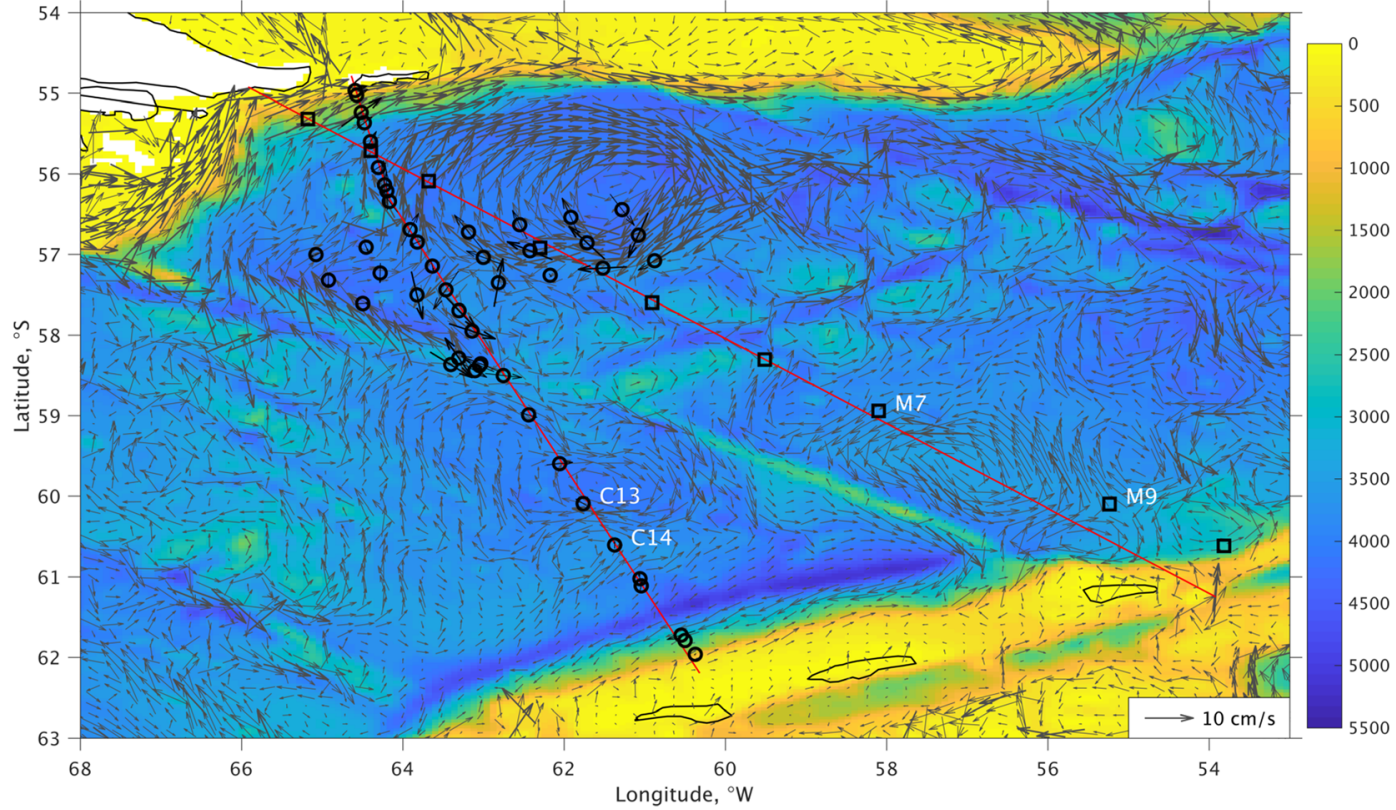

Figure 8. Horizontal distribution of modeled near-bottom (50 m above bottom) velocity overlaid on the model bathymetry (color shading), showing closed recirculations in the Yaghan Basin, Ona Basin, and in the deep basin southwest of the Shackleton Fracture Zone. The thicker vectors with a constant length scale of $10 \mathrm{~cm} / \mathrm{s}$ indicate strong currents $(10 \mathrm{~cm} / \mathrm{s}$ or higher). The black circles and squares are the locations of the cDrake and DRAKE observations, respectively. The two red lines indicate the model sections close to the cDrake trans-passage array, along which full-resolution and subsampled model transports are compared (Figure 10), and the DRAKE array, along which the modeled and observed surface geostrophic currents are compared (Figure 12). 


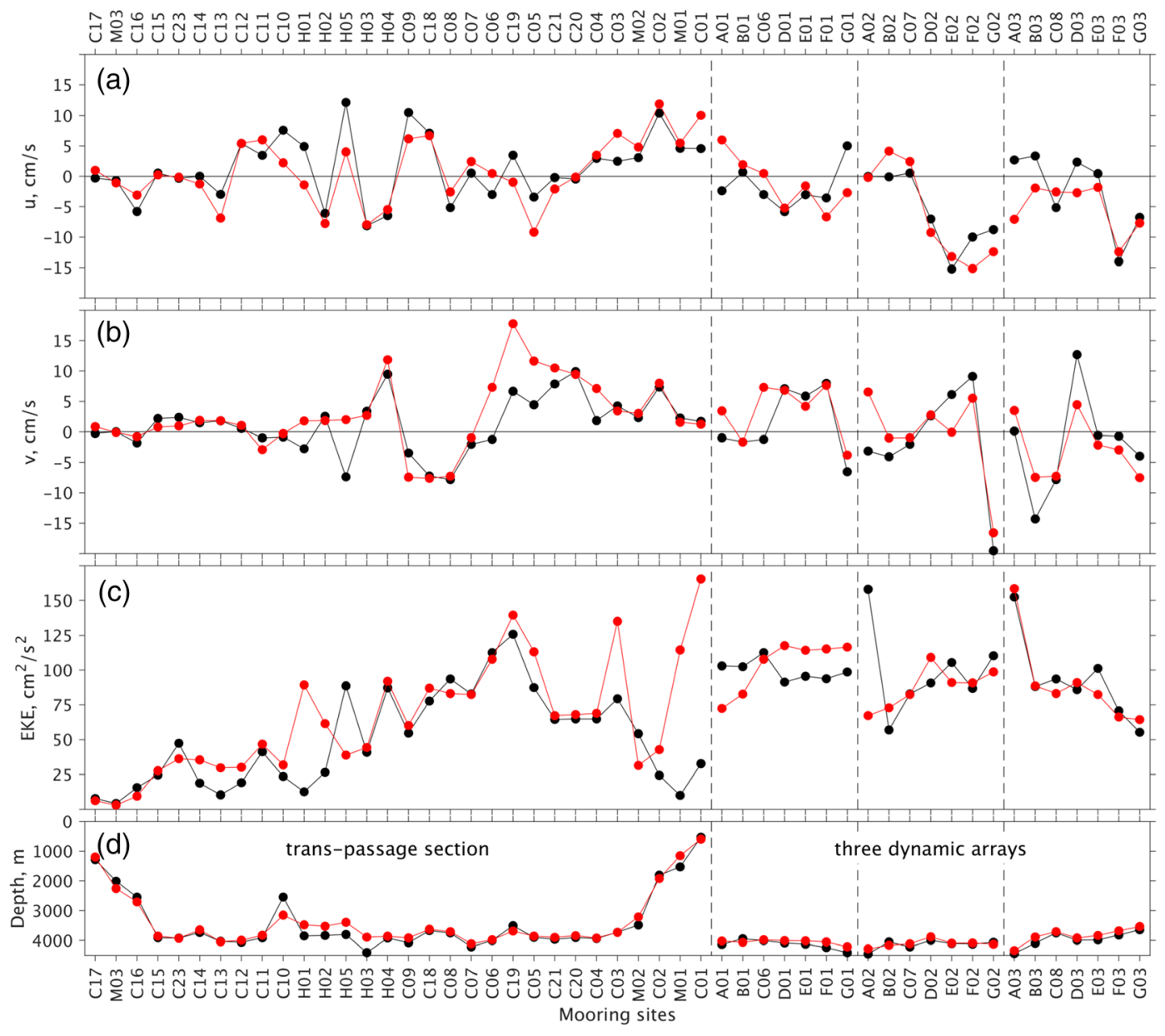

Figure 9. A comparison of the model results (red dots) and observations (black dots) at each of the cDrake mooring locations: (a) zonal velocity $\boldsymbol{u}$, (b) meridional velocity $\boldsymbol{v}$, (c) eddy kinetic energy (EKE), and (d) depth of mooring. The trans-passage section C17-C01 runs south to north; the three dynamic arrays in the Yaghan Basin run west to east (see Figures 1 and 8), with the northernmost line plotted first and the southernmost on the right.

thermal-wind equation as in observations (cyan line in Figure 6b) or (b) removing the barotropic component from the total transport (green line in Figure $6 \mathrm{~b}$ ). When the modeled baroclinic transport is computed using the thermal wind equation, it is essentially the same as the observed value computed from the 25 hydrographic surveys (135.0 and $135.3 \mathrm{~Sv}$, respectively). The modeled baroclinic transport profile, however, exhibits a faster decay $\left(\boldsymbol{z}_{\mathbf{0}}\right.$ of $\left.1,060 \mathrm{~m}\right)$ than the observations $\left(\boldsymbol{z}_{\mathbf{0}}\right.$ of $\left.1,210 \mathrm{~m}\right)$. The modeled baroclinic transport computed by removing the barotropic from the total transport (green line, Figure 6b) includes ageostrophic motions and is higher $(141.8 \mathrm{~Sv})$ than the transport computed from the thermal wind equation, but the profile has a decay scale $\left(\boldsymbol{z}_{\mathbf{0}}\right.$ of $\left.1,220 \mathrm{~m}\right)$ that is closer to the observations.

The agreement between the modeled and observed transports at the SR1b section extends to their temporal variability. Figure 7a shows the modeled monthly mean total and baroclinic transports (red and blue lines, respectively) together with the baroclinic transports computed for each of the 24 SR1b hydrographic surveys through 2018 (black dots; the last survey in 2020 is not included since it is beyond the model integration period). Other than the large outlier transport observed in 2015, the modeled transport exhibits the same range of variability as the observations (with standard deviations of 7.9 and $9.3 \mathrm{~Sv}$, respectively). It is worth noting that modeled variability of the total transport $(5.4 \mathrm{~Sv})$ is lower than that of the baroclinic transport $(7.9 \mathrm{~Sv})$, implying some compensation between baroclinic and barotropic components. We also find that the total and baroclinic transports are not correlated (correlation coefficient $r=0.23$ for the time series of monthly means), suggesting that the baroclinic transport cannot be used as a stand-alone measure of the total ACC 


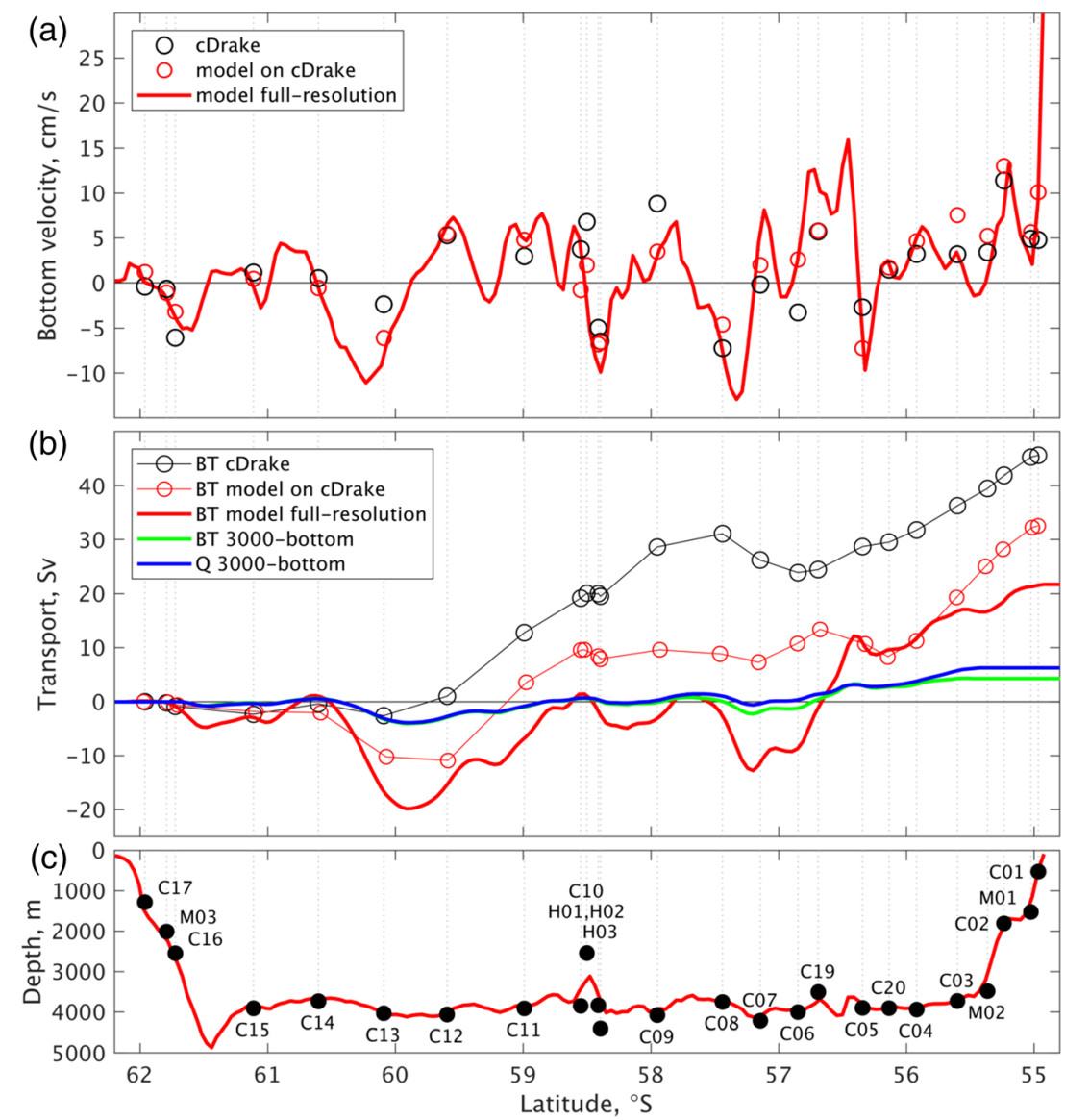

Figure 10. (a) Near-bottom velocity normal to the cDrake trans-passage section; red line is the modeled velocities along the full-resolution section (red line in Figure 8), and the red and black circles are the modeled and observed velocities at the mooring locations. (b) Cumulative from south to north transports along the trans-passage section: The circled black line is the barotropic transport (BT) based on cDrake observations (from Figure 3 in Donohue et al., 2016); the circled red line and thick red line are the modeled BT calculated using velocities subsampled at the cDrake mooring locations and the full model resolution, respectively. The thick green and blue lines are the modeled cumulative BT and total transport (Q), respectively, below 3,000 m. (c) Model bathymetry along the trans-passage section along with the mooring locations.

transport variability. In addition to the (baroclinic) transport, the repeat surveys along SR1b provide a good measure on how the mean temperature of the ACC has changed over time. There is a good agreement between the modeled and the observed mean transport-weighted potential temperature at the SR1b section (Figure $7 \mathrm{~b}$ ). Both exhibit significant interannual variability but without an obvious long-term trend from 1993 to 2018.

\section{3. cDrake and DRAKE Mooring Sections}

The difference in total transport between the cDrake and the DRAKE estimates (173.3 vs. $141 \mathrm{~Sv}$ ) is due to the large difference in barotropic component (45.6 vs. $5 \mathrm{~Sv}$ ); the baroclinic component is actually lower in cDrake than in DRAKE estimates (127.7 vs. $136 \mathrm{~Sv}$ ). The modeled transport components, on the other hand, are essentially the same between these two sections (21.7 vs. $20.1 \mathrm{~Sv}$ in barotropic and 135.0 vs. 137.2 Sv in baroclinic transports). Therefore, the key to understanding the difference lies in the barotropic components or the near-bottom flow.

The modeled deep flow in Drake Passage (Figure 8) is significantly more complex than the corresponding upper ocean circulation (Figure 3), reflecting the influence of the bottom bathymetry in blocking and steering the flow. At least three regions of recirculating gyres can be identified. First, there is a strong (mean velocity over $10 \mathrm{~cm} / \mathrm{s}$ ) clockwise recirculation in the deep Yaghan Basin north of the West Scotia Ridge. This 


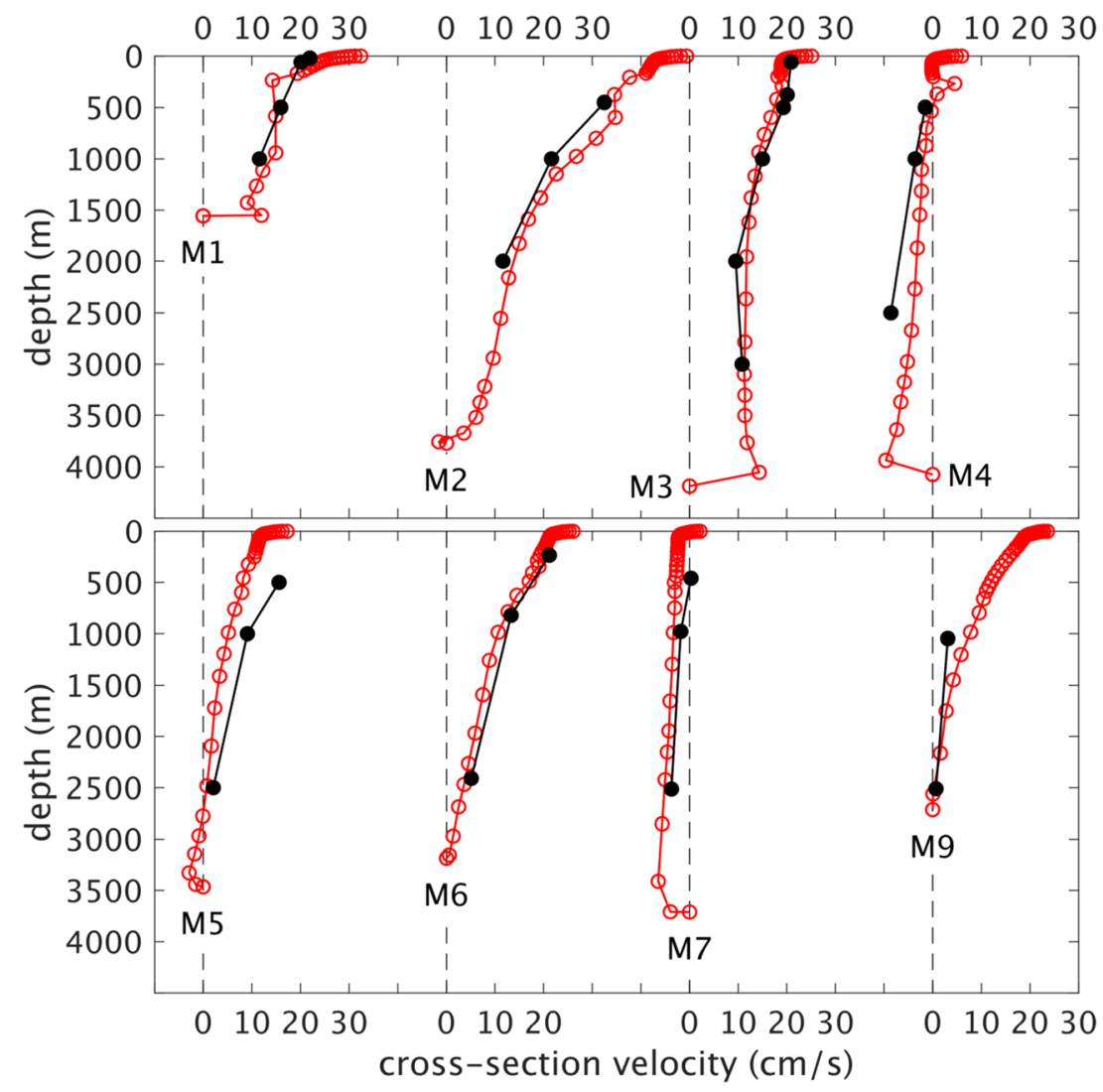

Figure 11. Vertical profile of the time mean cross-section velocity at 8 DRAKE mooring locations. The black dots are observations from Table 3 in Koenig et al. (2014), and red circles are model results.

recirculation is well sampled in the south and southwest by the dense observations of cDrake and, to a lesser degree, by the DRAKE M3 and M4 mooring sites. Second, in the Ona Basin south of the West Scotia Ridge there is a strong counterclockwise recirculation. This recirculation is only partially resolved by the DRAKE moorings due to the large gap between M7 and M9 (see Figure 8; the mooring M8 in between was lost). Finally, there exist both clockwise and counterclockwise recirculation cells to the southwest of the Shackleton Fracture Zone, where the southern portion of the cDrake array was sited. These recirculation cells pose a real challenge when designing mooring arrays to accurately estimate the transport.

The near-bottom moored observations of cDrake provide an excellent benchmark for evaluating the model mean barotropic transport (i.e., that derived from the bottom flow). With the exception of a few sites (e.g., C01, C03, H01, H05, and C13 in Figure 9), both near-bottom velocity and EKE are in good agreement between model and observations at the 48 cDrake moorings. The model shows the same level of enhanced EKE values in the deep Yaghan Basin $\left(\sim 100 \mathrm{~cm}^{2} / \mathrm{s}^{2}\right)$ as the observations. Where then does the difference in barotropic transports (21.7 vs. $45.6 \mathrm{~Sv}$ in model and observations, respectively) arise?

To address this, we show in Figure 10a the observed near-bottom velocity normal to the section at the mooring sites (black circles) along with the modeled velocities at the mooring sites (red circles) and at the full model resolution (thick red line) and in Figure 10b the corresponding barotropic transports cumulative along the section. The results show that the 23.9 Sv transport difference comes from two sources: (1) $13 \mathrm{~Sv}$ due to the model-data velocity difference at the mooring sites (red vs. black lines with circles in Figure 10b); (2) 10.9 Sv due to subsampling (red line with circles vs. thick red line in Figure 10b). If we consider the 10.9 Sv due to subsampling, this is larger than the cDrake sampling error estimates $(1.8,2.8$, and 4.6 Sv for the southern slope, near the Shackleton Fracture Zone and within the array outside the steeply sloping topography, respectively, Donohue et al., 2016). 


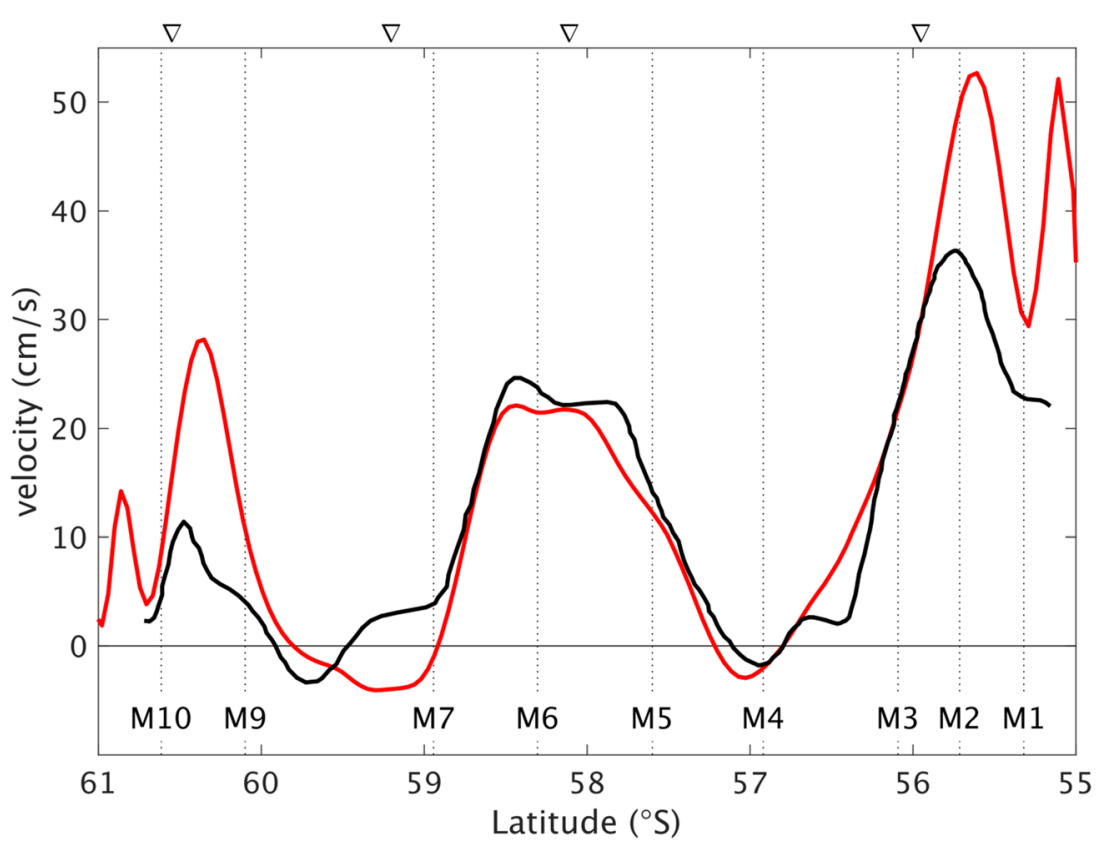

Figure 12. Horizontal distribution of the surface geostrophic current normal to the DRAKE section as a function of latitude. The black line is from Koenig et al. (2014, green line in their Figure 8); with the dashed dot lines denoting the latitudes of the DRAKE moorings. The red line is the time-mean surface geostrophic velocity calculated from model sea surface height. The four triangles in panel (a) from north to south denote the locations of SAF, PF, SACCF, and SBby from Orsi et al. (1995) based on hydrographic data (colored lines in Figure 3).

Most of the barotropic transport differences between model and observations occur south of $58.5^{\circ} \mathrm{S}$. Here, the cDrake section meets with the Shackleton Fracture Zone (mooring C10), and the cumulative barotropic transport should be zero since the near-bottom flow cannot cross the shallow $(<3,000 \mathrm{~m})$ ridge. In fact, below $3,000 \mathrm{~m}$ the cumulative barotropic transport is nearly identical to the cumulative total transport (green and blue lines in Figure 10b, respectively) and both reach zero net transport at $58.5^{\circ} \mathrm{S}$. Therefore, we argue that, just as in the subsampled model, the calculations using the cDrake array in Donohue et al. (2016) overestimate the mean barotropic contribution in part because the array undersamples the recirculation southwest of the Shackleton Fracture Zone (Figure 8). The cDrake array also undersamples the near bottom flows northeast of Shackleton Fracture Zone, but the net effect is small as an underestimation of the barotropic transport between $\mathrm{C} 08$ and $\mathrm{C} 05$ is canceled out by an overestimation between $\mathrm{C} 03$ and $\mathrm{C} 01$. This implies that cDrake likely overestimates the barotropic transport by $10 \mathrm{~Sv}$ (the difference between fully resolution and undersampled section in the model results) to $20 \mathrm{~Sv}$ (the cumulative transport estimated in cDrake at $\mathrm{C} 10$, where we expect the value to be close to zero). Thus, a rough revised cDrake barotropic transport would be in the order of $30 \pm 5 \mathrm{~Sv}$.

We now address why the DRAKE transport is lower than the cDrake and model transports. The model agrees well with the DRAKE observations on vertical profiles of mean velocity normal to the DRAKE section at the eight mooring sites (Figure 11). The flow is westward at M4 and M7 and eastward elsewhere. The model velocities are slightly stronger at M2 (in the SAF) and weaker at M5 and M6 (in the PF), similar to the differences from SADCP velocities (Figure 4). The DRAKE moorings are widely spaced (Figure 1), and their estimate of the mean transport relies heavily on a mean dynamic topography (MDT) estimate, in this case the CNES-CLS09 (Rio et al., 2011) and CNES-CLS13 (Rio et al., 2014); see Koenig et al. (2014) for details. The reader is also referred to Griesel et al. (2012) for a discussion on the challenges of usig MDT to infer the ACC transport. The modeled and observed surface geostrophic currents across the DRAKE section have a similar spatial pattern (Figure 12), but the modeled currents are quite a bit stronger both north of $56^{\circ} \mathrm{S}$ (SAF) and south of $60^{\circ} \mathrm{S}$ (SACCF/SBdy) and slightly weaker in $57-59.5^{\circ} \mathrm{S}$ (PF/SACCF). The average surface geostrophic velocity from DRAKE is $11.7 \mathrm{~cm} / \mathrm{s}$, corresponding to a transport rate of $0.110 \mathrm{~Sv}$ per meter, whereas the model has an average surface geostrophic velocity of $13.5 \mathrm{~cm} / \mathrm{s}$ across the DRAKE section or 
$0.127 \mathrm{~Sv}$ per meter. Since the model surface velocity matches well with surface currents directly measured by SADCP (Figure 6a), we argue that DRAKE results may underestimate the surface geostrophic velocities, resulting in underestimated total transport. The underestimation in surface currents is found primarily in the fronts over the slopes (Figure 12), possibly because of an error in the mean dynamic topography, and this shows up in the barotropic transport (5 Sv in DRAKE vs. 20.1 Sv in model). The DRAKE barotropic transport of $5 \mathrm{~Sv}$ is quite small when compared to the model and the transports at the upstream (cDrake) and downstream (SR1b) sections. We therefore argue that the modeled barotropic transport $(\sim 20 \mathrm{~Sv})$ is a more appropriate estimate for the DRAKE section.

\section{Summary and Conclusion}

An accurate knowledge of the ACC transport-its vertical and horizontal structure as well as its temporal variability-is fundamental to our understanding of its role in global ocean circulation. Yet, despite the tremendous observational efforts (e.g., Chidichimo et al., 2014; Cunningham et al., 2003; Donohue et al., 2016; Firing et al., 2011; Koenig et al., 2014) since the early ISOS program in quantifying the time-mean ACC transport through Drake Passage, uncertainty about the total transport remains.

In this study, we compared the modeled ACC in a multi-decadal, $1 / 12^{\circ}$ global simulation with observations in Drake Passage and used the validated model results to interpret the transport estimates of the DRAKE and cDrake campaigns and to reconcile their differences. We argued that the model time-mean ACC transport of 157.3 Sv, approximately the average of the DRAKE and cDrake estimates, is representative of the time-mean ACC transport for the following reasons:

i The modeled transport rate per unit depth within the top $1,000 \mathrm{~m}$ is in excellent agreement with the directly measured SADCP results (Firing et al., 2011).

ii The exponential decay of the baroclinic transport as a function of depth over the full water column is consistent with the profile determined from repeat hydrographic surveys at SR1b.

iii The larger/smaller barotropic transports estimated by cDrake/DRAKE can both be explained as resulting from spatial resolution. The cDrake array appears to undersample the recirculation in the deep basin southwest of the Shackleton Fracture Zone, particularly the strong westward flow between cDrake moorings $\mathrm{C} 13$ and $\mathrm{C} 14$. On the other hand, the surface geostrophic currents derived in DRAKE (Koenig et al., 2014) underestimate or exclude large eastward transports found in the model both in north (SAF) and south (SACCF/SBdy) and yield a lower surface transport rate than both the model and the SADCP measurements.

It is worth noting that the time-mean total ACC transport reported in this study is close to the one derived by data-constrained models: (1) a 25-year mean transport of $155 \mathrm{~Sv}$ in the 1/12 ${ }^{\circ}$ Mercator ocean reanalysis GLORYS12 (1993-2017) as reported by Artana et al. (2019); (2) a 22-year mean transport of $150 \mathrm{~Sv}$ in the HYCOM-based $1 / 12^{\circ}$ ocean reanalysis GOF3.1 (1994-2015); (3) a 6-year mean transport of 149 Sv in the $1 / 6^{\circ}$ Southern Ocean State Estimate (SOSE) (2005-2010) as reported by Peña-Molino et al. (2014); and (4) an ensemble long-term mean transport of $152 \mathrm{~Sv}$ (with however a large $34 \mathrm{~Sv}$ spread) from nine ocean reanalysis products with horizontal resolution ranging from $1^{\circ}$ to $1 / 4^{\circ}$ and timescale from 22 to 67 years as reported by Uotila et al. (2019).

Our results indicate that the baroclinic and barotropic transports are not correlated, and thus, that monitoring either component alone may be insufficient to assess the temporal variability of the total ACC transport. Quantifying the barotropic transport and its variability would require sustained high-resolution measurements covering the entire passage, including not only the deep SAF and PF but also the deep recirculations both north and south of the Shackleton Fracture zone or West Scotia Ridge: either moored near-bottom sensors to directly measure the barotropic (bottom reference) transport or full-depth profiles to enable the use of proxies based on surface or boundary measurements. Achieving this sort of spatial and temporal coverage remains a challenge, and here the numerical models become valuable-provided that they represent key features of the observed ACC realistically.

From an observational point of view, repeat SADCP surveys provide the most efficient way to directly measure transport in the upper $1,000 \mathrm{~m}$. This has proven to be the case in other locations, that is, across the Gulf Stream (e.g., Rossby et al., 2019), in the northern North Atlantic near $60^{\circ} \mathrm{N}$ (Chafik et al., 2014), and over the 
Iceland-Shetland Ridge (Rossby et al., 2018). The SADCP transects across Drake Passage now cover a much longer period than the 4.5 years initially presented in Firing et al. (2011), and in conjunction with information on deep structure and variability from both observations and high-resolution numerical models like the one described here, they could provide robust estimates for the time-mean ACC transport and refine error estimates for transports observed with sparse arrays.

\section{Data Availability Statement}

The full-resolution model outputs are stored in the ERDC archive server, and the model results presented in this study are available online (http://doi.org/10.5281/zenodo.3887144). The SR1b hydrographic data collection was supported by NERC National Capability funding and forms part of the Global Ship-based Hydrographic Investigations Program (GO-SHIP; http://www.go-ship.org). The SR1b data are available from the British Oceanographic Data Centre (http://projects.noc.ac.uk/drake-passage/cruises-and-data). cDrake CPIES data are available from NOAA, National Centers for Environmental Information, Accession 0121256.

\section{Acknowledgments}

X.X. and E.P.C. are supported by the U. S. National Science Foundation Physical Oceanography Program (award 1537136) and by the Office of Naval Research (N00014-19-12717). Y. L.F. is supported by U.K. Natural Environment Research Council grant NE/N018095/1. The global ocean-sea ice simulation was performed on supercomputers at the U.S. Army Engineer Research and Development Center (ERDC) in Vicksburg, Mississippi, and the U.S. Navy DoD Supercomputing Resource Center (DSRC) in Stennis Space Center, Mississippi, using computer time provided by the U.S. DoD High Performance Computing Modernization Program.

\section{References}

Artana, C., Ferrari, R., Bricaud, C., Lellouche, J.-M., Garric, G., Sennéchael, N., et al. (2019). Twenty-five years of Mercator ocean reanalysis GLORYS12 at Drake Passage: Velocity assessment and total volume transport. Advances in Space Research. https://doi.org/10.1016/j. asr.2019.11.033

Bleck, R. (2002). An oceanic general circulation model framed in hybrid isopycnic-Cartesian coordinates. Ocean Modelling, 37, 55-88.

Bohoyo, F., Larter, R. D., Galindo-Zaldívar, J., Leat, P. T., Maldonado, A., Tate, A. J., et al. (2019). Morphological and geological features of Drake Passage, Antarctica, from a new digital bathymetric model. Journal of Maps, 15(2), 49-59. https://doi.org/10.1080/ 17445647.2018.1543618

Carnes, M. R. (2009). Description and evaluation of GDEM-V3.0. Tech. Rep. NRL/MR/7330-09-9165, 21 pp., naval research laboratory, Stennis Space Center, Mississippi.

Chafik, L., Rossby, T., \& Schrum, C. (2014). On the spatial structure and temporal variability of poleward transport between Scotland and Greenland. Journal of Geophysical Research: Oceans, 119, 824-841. https://doi.org/10.1002/2013JC009287

Chassignet, E. P., Smith, L. T., Halliwell, G. R., \& Bleck, R. (2003). North Atlantic simulations with the hybrid coordinate ocean model (HYCOM): Impact of the vertical coordinate choice, reference pressure, and thermobaricity. Journal of Physical Oceanography, 33(12), 2504-2526. https://doi.org/10.1175/1520-0485(2003)033\%3C2504:NASWTH\%3E2.0.CO;2

Chassignet, E. P., Yeager, S. G., Fox-Kemper, B., Bozec, A., Castruccio, F., Danabasoglu, G., et al. (2020). Impact of horizontal resolution on global ocean-sea-ice model simulations based on the experimental protocols of the Ocean Model Intercomparison Project phase 2 (OMIP-2). Geoscientific Model Development. https://doi.org/10.5194/gmd-2019-374-RC2

Chidichimo, M. P., Donohue, K. A., Watts, R. D., \& Tracey, K. L. (2014). Baroclinic transport time series of the Antarctic Circumpolar Current measured in Drake Passage. Journal of Physical Oceanography, 44(7), 1829-1853. https://doi.org/10.1175/JPO-D-13-071.1

Cunningham, S. A., Alderson, S. G., King, B. A., \& Brandon, M. A. (2003). Transport and variability of the Antarctic circumpolar current in drake passage. Journal of Geophysical Research, 108(C5), 8084. https://doi.org/10.1029/2001JC001147

Donohue, K. A., Tracey, K. L., Watts, D. R., Chidichimo, M. P., \& Chereskin, T. K. (2016). Mean Antarctic Circumpolar Current transport measured in Drake Passage. Geophysical Research Letter, 43, 11,760-11,767. https://doi.org/10.1002/2016GL070319

Firing, Y. L., Chereskin, T. K., \& Mazloff, M. R. (2011). Vertical structure and transport of the Antarctic Circumpolar Current in Drake Passage from direct velocity observations. Journal of Geophysical Research, 116, C08015. https://doi.org/10.1029/2011JC006999

Gordon, A. L. (1986). Interocean exchange of thermocline water. Journal of Geophysical Research, 91(C4), 5037-5046. https://doi.org/ 10.1029/JC091iC04p05037

Griesel, A., Mazloff, M. R., \& Gille, S. T. (2012). Mean dynamic topography in the Southern Ocean: Evaluating Antarctic Circumpolar Current transport. Journal of Geophysical Research, 117(C1), C01020. https://doi.org/10.1029/2011JC007573

Hallberg, R., \& Gnanadesikan, A. (2006). The role of eddies in determining the structure and response of the wind-driven Southern Hemisphere overturning: Results from the Modeling Eddies in the Southern Ocean (MESO) project. Journal of Physical Oceanography, 36(12), 2232-2252. https://doi.org/10.1175/JPO2980.1

Hallberg, R., \& Gnanadesikan, A. (2001). An exploration of the role of transient eddies in determining the transport of a zonally reentrant current. Journal of Physical Oceanography, 31(11), 3312-3330. https://doi.org/10.1175/1520-0485(2001)031\%3C3312:aeotro\%3E2.0.co;2

Hogg, A. M. C., Meredith, M. P., Chambers, D. P., Abrahamsen, E. P., Hughes, C. W., \& Morrison, A. K. (2015). Recent trends in the Southern Ocean eddy field. Journal of Geophysical Research: Oceans, 120, 257-267. https://doi.org/10.1002/2014JC010470

Hughes, C. W., Meredith, M. P., \& Heywood, K. (1999). Wind-driven transport fluctuations through Drake Passage: A southern mode. Journal of Physical Oceanography, 29(8), 1971-1992. https://doi.org/10.1175/1520-0485(1999)029\%3C1971:WDTFTD\%3E2.0.CO;2

Hughes, C. W., Williams, J., Coward, A. C., \& de Cuevas, B. A. (2014). Antarctic circumpolar transport and the southern mode: A model investigation of interannual to decadal timescales. Ocean Science, 10(2), 215-225. https://doi.org/10.5194/os-10-215-2014

Hunke, E. C., \& W. H. Lipscomb (2008). CICE: The Los Alamos Sea ice model documentation and software user's manual, version 4.0, Tech. Rep. LA-CC-06-012, los Alamos National Laboratory, Los Alamos, New Mexico.

Killworth, P. D. (1992). An equivalent-barotropic mode in the fine resolution Antarctic model. Journal of Physical Oceanography, 22(11), 1379-1387. https://doi.org/10.1175/1520-0485(1992)022\%3C1379:AEBMIT\%3E2.0.CO;2

Kim, Y. S., \& Orsi, A. H. (2014). On the variability of Antarctic Circumpolar Current fronts inferred from 1992-2011 altimetry. Journal of Physical Oceanography, 44(12), 3054-3071. https://doi.org/10.1175/JPO-D-13-0217.1

Koenig, Z., Provost, C., Ferrari, R., Sennechael, N., \& Rio, M.-H. (2014). Volume transport of the Antarctic Circumpolar Current: Production and validation of a 20 year long time series obtained from in situ and satellite observations. Journal of Geophysical Research: Oceans, 119, 5407-5433. https://doi.org/10.1002/2014JC009966 
LaCasce, J. H., \& Isachsen, P. E. (2010). The linear models of the ACC. Progress in Oceanography, 84(3-4), 139-157. https://doi.org/10.1016/ j.pocean.2009.11.002

Marshall, J., \& Speer, K. (2012). Closure of the meridional overturning circulation through Southern Ocean upwelling. Nature Geoscience, 5(3), 171-180. https://doi.org/10.1038/ngeo1391

Meredith, M. P., \& Hughes, C. W. (2005). On the sampling timescale required to reliably monitor interannual variability in the Antarctic circumpolar transport. Geophysical Research Letter, 32, L03609. https://doi.org/10.1029/2004GL022086

Meredith, M. P., Woodworth, P. L., Chereskin, T. K., Marshall, D. P., Allison, L. C., Bigg, G. R., et al. (2011). Sustained monitoring of the Southern Ocean at Drake Passage: Past achievements and future priorities. Reviews of Geophysics, 49, RG4005. https://doi.org/10.1029/ 2010RG000348

Meredith, M. P., Woodworth, P. L., Hughes, C. W., \& Stepanov, V. (2004). Changes in the ocean transport through Drake Passage during the 1980s and 1990s, forced by changes in the Southern Annular Mode. Geophysical Research Letter, 31, L21305. https://doi.org/10.1029/ 2004GL021169

Morrison, A. K., \& Hogg, A. (2013). On the relationship between Southern Ocean overturning and ACC transport. Journal of Physical Oceanography, 43(1), 140-148. https://doi.org/10.1175/JPO-D-12-057.1

Munday, D. R., Johnson, H. L., \& Marshall, D. P. (2013). Eddy saturation of equilibrated circumpolar currents. Journal of Physical Oceanography, 43(3), 507-532. https://doi.org/10.1175/JPO-D-12-095.1

Olbers, D., Borowski, D., Völker, C., \& Wölff, J.-O. (2004). The dynamical balance, transport and circulation of the Antarctic Circumpolar Current. Antarctic Science, 16(4), 439-470. https://doi.org/10.1017/s0954102004002251

Orsi, A. H., Whitworth, T. III, \& Nowlin, W. D. Jr. (1995). On the meridional extent and fronts of the Antarctic Circumpolar Current. Deep Sea Research Part I: Oceanographic Research Papers, 42(5), 641-673. https://doi.org/10.1016/0967-0637(95)00021-W

Peña-Molino, B., Rintoul, S. R., \& Mazloff, M. R. (2014). Barotropic and baroclinic contributions to along-stream and across-stream transport in the Antarctic Circumpolar Current. Journal of Geophysical Research: Oceans, 119, 8011-8028. https://doi.org/10.1002/ 2014JC010020

Rio, M., Guihenut, S., \& Larnicol, G. (2011). New CNES-CLS09 global mean dynamic topography computed from the combination of GRACE data, altimetry and in situ measurements. Journal of Geopysical Research, 116, C07018. https://doi.org/10.1029/2010JC006505

Rio, M., Mulet, S., \& Picot, N. (2014). Beyond GOCE for the ocean circulation estimate: Synergetic use of altimetry, gravimetry, and in situ data provides new insight into geostrophic and Ekman currents. Geophysical Research Letter, 41, 8918-8925. https://doi.org/10.1002/ 2014GL061773

Rossby, T., Flagg, C., Chafik, L., Harden, B., \& Søiland, H. (2018). A direct estimate of volume, heat, and freshwater exchange across the Greenland-Iceland-Faroe-Scotland Ridge. Journal of Geophysical Research: Oceans, 123, 7139-7153. https://doi.org/10.1029/ 2018JC014250

Rossby, T., Flagg, C. N., Donohue, K., Fontana, S., Curry, R., Andres, M., \& Forsyth, J. (2019). Oleander is more than a flower: Twenty-five years of oceanography aboard a merchant vessel. Oceanography, 32(3), 126-137. https://doi.org/10.5670/oceanog.2019.319

Sallée, J.-B., Speer, K., \& Morrow, R. (2008). Response of the Antarctic Circumpolar Current to atmospheric variability. Journal of Climate, 21(12), 3020-3039. https://doi.org/10.1175/2007JCLI1702.1

Schmitz, W. J. Jr. (1996). On the World Ocean Circulation: Volume I. Technical Report, WHOI-96-03. 140 pp.

Sverdrup, H. U. (1933). On vertical circulation in the ocean due to the action of the wind with application to conditions within the Antarctic Circumpolar Current. Discovery Reports, VII, 139-170.

Sokolov, S., \& Rintoul, S. R. (2009). Circumpolar structure and distribution of the Antarctic Circumpolar Current fronts: 1. Mean circumpolar paths. Journal of Geophysical Research, 114, C11018. https://doi.org/10.1029/2008JC005108

Talley, L. D. (2013). Closure of the global overturning circulation through the Indian, Pacific, and Southern Oceans: Schematics and transports. Oceanography, 26(1), 80-97. https://doi.org/10.5670/oceanog.2013.07

Thompson, D. W. J., \& Solomon, S. (2002). Interpretation of recent Southern Hemisphere climate change. Science, 296(5569), 895-899. https://doi.org/10.1126/science.1069270

Tsujino, H., Urakawa, S., Nakano, H., Small, R. J., Kim, W. M., Yeager, S. G., et al. (2018). JRA-55 based surface dataset for driving oceansea-ice models (JRA55-do). Ocean Modelling, 130, 79-139. https://doi.org/10.1016/j.ocemod.2018.07.002

Uotila, P., Goosse, H., Haines, K., Chevallier, M., Barthélemy, A., Bricaud, C., et al. (2019). An assessment of ten ocean reanalyses in the polar regions. Climate Dynamics, 52(3-4), 1613-1650. https://doi.org/10.1007/s00382-018-4242-Z

Whitworth, T. III (1983). Monitoring the transport of the Antarctic Circumpolar Current at Drake Passage. Journal of Physical Oceanography, 13(11), 2045-2057. https://doi.org/10.1175/1520-0485(1983)013\%3C2045:MTTOTA\%3E2.0.CO;2

Whitworth, T. III, \& Peterson, R. G. (1985). Volume transport of the Antarctic Circumpolar Current from bottom pressure measurements. Journal of Physical Oceanography, 15(6), 810-816. https://doi.org/10.1175/1520-0485(1985)015\%3C0810:VTOTAC\%3E2.0.CO;2 